\title{
Full-English Teaching Study of Audit and Assurance Service
}

\author{
Yanhong Pang ${ }^{1}$ \\ ${ }^{1}$ Professor of Nanjing Audit University, China \\ Correspondence: Yanhong Pang, Professor of Nanjing Audit University, China. E-mail: \\ Pangyanhong@nau.edu.cn \\ Received: October 7, 2019 \\ Accepted: November 1, 2019 \\ Online Published: November 10, 2019 \\ doi:10.5539/ijbm.v14n12p121 \\ URL: https://doi.org/10.5539/ijbm.v14n12p121
}

\begin{abstract}
With the continuous enhancement of economic globalization and world economic integration as well as the further opening of the entire society, the demand for financial and economic professionals with an international perspective is on the rise. Therefore, various forms of full-English teaching have been tried in many higher education institutions. However, at present, the full-English teaching of professional courses in Chinese higher education institutions is still in the preliminary exploration stage. Based on the analysis of the characteristics of the full- English course, Audit and Assurance Service, of Nanjing Audit University, this paper summarizes the teaching practice of the full-English course of auditing from the construction of teaching team, the design of teaching contents and the evaluation methods, and so on. It hopes to provide reference for the development of full-English teaching of professional course in Chinese higher education institutions.
\end{abstract}

Keywords: full-english teaching, audit and assurance service, semester project

\section{Introduction}

With the continuous enhancement of economic globalization and world economic integration as well as the further opening of the entire society, the demand for financial and economic professionals with an international perspective is on the rise. In recent years, auditing education has developed vigorously and the flow of audit human resources across borders and regions has been increasingly enhanced. Therefore, audit teaching is becoming more and more internationalized. In order to meet the requirement of the international standards, bilingual teaching emerges as a new teaching mode in many colleges and universities in China. Since the issuance of "Opinions of Ministry of Finance and the Ministry of Education on Implementing the Project of Undergraduate Teaching Quality and Teaching Reform in Colleges and Universities", bilingual teaching has made some achievements in colleges and universities. In the meanwhile, some defects have also been exposed, such as the difficulty of controlling the degree of bilingualism, students' over-reliance on Chinese interpretation, and so on. Therefore, various forms of full-English teaching have been tried in many higher education institutions. However, at present, the full-English teaching of professional courses in Chinese higher education institutions is still in the preliminary exploration stage.

Nanjing Audit University is the only financial and economical institute of higher education around the world that carries "audit" in its name. Adhering to the concept of "quality, characteristics and internationalization", it is committed to cultivating high-level and application-oriented talents with an international perspective. Auditing is a special construction major of the Ministry of Education, a Pilot Program of Professional Comprehensive Reform of the Ministry of Education, a Key Major in the 12th Five-year Plan of Jiangsu Province, and a major of the Top-notch Academic Programs Project of Jiangsu Higher Education Institutions. Audit and Assurance Service is one of the core courses of auditing major, and plays a particularly important role in personnel training. With the advancement of internationalization of universities, the demand for full-English teaching of this course is increasing. Audit and Assurance Service has become the backbone of the international cooperative education project and has been selected as one of the Jiangsu Provincial Excellent English Teaching Courses for Foreign Students of 2016. As one of core courses of ACCA direction (Chartered Institute of Certified Public Accountants) of auditing major, Audit and Assurance Service was first established in 2006. With the development of international cooperation, Nanjing Audit University joined the IAEP (Internal Audit Education Partnership) project in September 2007. Two years later, it began to enroll the first undergraduates of IAEP direction of auditing major and Audit and Assurance Service became one of key courses of this international project. With the increasing of international influence of the university, the proportion of exchange students and international 
students from overseas (e.g. Malaysia, South Africa, Morocco, Italy, etc.) is increasing. Due to its profession and full-English teaching, it has become one of the welcome courses for international students. Therefore, it is a truly "international" professional compulsory course. Full- English teaching can enhance students' ability to master the latest knowledge in the field of economics and management, especially in auditing field, improve their internationalization level and cross-cultural communication ability, and cultivate high-quality and international applied talents. After learning this course, students can not only receive audit professional knowledge, but also understand and master audit theory knowledge comprehensively and systematically, improve the ability of applying English, and lay a solid theoretical foundation and practical operation skills for audit work. Because of its remarkable teaching effect, Nanjing Audit University has been certified by IIA as the only IAEP cooperative level university in China, which can carry out student exchanges, teacher recruitment, credit recognition and scientific research cooperation with global partner universities. It has been rated by the British ACCA as "the Largest University to Cultivate ACCA Talents" and the "Platinum Level Training Institution".

Taking the full-English teaching course of Audit and Assurance Service as an example, this paper summarizes the teaching practice of the full-English course of auditing from the construction of teaching team, the design of teaching contents and the evaluation methods, and so on. It hopes to provide reference for the development of full-English teaching of professional course in Chinese higher education institutions.

\section{Literature Review of Full-English Teaching}

From the 1970 s to the 1980 s, foreign researches on full-English teaching outside China mainly include the teaching efficiency and academic achievements in different disciplines, and after the 1990s, they began to focus on the role of language in power, management, governance and the pursuit of equality ( $\mathrm{Li}, 2017)$. After entering the new century, the researches mainly studies the teacher's classroom language strategy (Sharpe, 2008), teaching effect on a subject (Wette \& Hawken, 2016), and students' knowledge construction in their respective fields and the knowledge structure balance among different subjects (Kuteeva \& Negretti, 2016). Before the new century, there are few papers on bilingual or full-English teaching in China. In recent years, with the continuous enhancement of economic globalization and world economic integration as well as the further opening of the entire society, more and more literatures of full-English teaching of professional courses in Chinese universities appears. They mainly include teaching on Chinese students, foreign students and on Chinese and foreign students.

Firstly, full English teaching on Chinese students mainly is embodied manifested in the following aspects: (1) Investigation and analysis of teaching contents and mode. Zhu (2005) investigates the English immersion education of business English program. Some suggestions for improvement of the approach have also been pointed out. Ma et al. (2019) study the teaching contents, teaching mode and assessment form of the course of Automatic Control Theory and put forward the construction methods and existing problems of the course. (2) Teaching effect evaluation. Xin et al. (2012) introduces the United States Medical Examination (USMIE) in evaluating the effect of English--immersed class of Medical and Immunology and concludes that it is a good choice to use USMLE for the evaluation of English-immersed teaching. Zhou et al. (2018) concludes that full-English teaching has more advantages than bilingual teaching in improving students 'ability of listening, speaking and understanding which is based on the analysis of the questionnaire. Most students believe that teaching in English only will make them more focused in the classroom. However, full-English teaching should be implemented gradually. Li (2017) believes that the comprehensive cognitive level and English ability of learners greatly restrict the effect of EMI teaching. Students with weak English basis will lose more professional knowledge if they focus on trying to understand the meaning of English language. Students with good English basis and high subjective initiative, EMI courses will play a strong role in promoting students' ability.

Secondly, full-English teaching for foreign students. Deng et al. (2006) describe the methods and experiences of Hnatomy, Histology and Embryology teaching in English for foreign students. Wu, Hongyan et al. (2008) shares English teaching experience for foreign students in western medicine universities and Wang (2010) examines English teaching practice for Indian Medical Students. Yu and Yang (2018) point out that there are problems in the full-English teaching of international students' professional courses, such as shortage of teachers, and backward teaching philosophy, and so forth. In order to promote the education level of international students, specific measures should be taken in the universities, including establishment of a full-English teacher training system, improvement of the full-English teaching concepts and teaching methods of professional courses, and enhancing interaction with foreign students.

Thirdly, full-English teaching for both Chinese and foreign students. Sun (2017) makes a comparison of English learning anxiety between Chinese and foreign students. He believes that the anxiety level of foreign students is 
slightly higher than Chinese students. No significant different difference of anxiety value between male, and female foreign students, however obvious difference between male and female Chinese students. It can be ranked according to the anxiety score: Chinese male student $>$ foreign male student $>$ foreign female. Therefore, the English learning anxiety of students should be faced up when adopting strategies to improve learning effect.

As mentioned above, some research results have been made in full-English teaching on professional courses. However, full-English teaching research on auditing of both Chinese and foreign students has not been done. This is just what the paper will discuss.

\section{Characteristics of Full-English Teaching of Audit and Assurance Service}

\subsection{Reasonable Full-English Teaching Team Building}

Compared with the traditional Chinese professional courses, the teaching of full-English course has higher requirements for the teaching staff. At present, the lack of teachers for full-English teaching in universities is still a common phenomenon, which is the biggest obstacle to promoting full-English teaching. However, Nanjing Audit University attaches great importance to the construction of full-English teaching staff. There are four teachers in Audit and Assurance Service teaching group, including local and "returned" overseas teachers. First of all, the age structure, educational background, knowledge structure, and professional title structure are reasonable. In terms of age, $100 \%$ of teachers are young and middle-aged, $50 \%$ of them are under 40 years old, and $50 \%$ of them are between 36 and 45 years old. In terms of academic degree, $75 \%$ of teachers have Ph.D. or $\mathrm{Ph} . \mathrm{D}$. in studying. In terms of knowledge structure, all teachers specialized in accounting and auditing. In terms of academic background, they graduated from Tohoku University (Japan) (25\%), Wuhan University (25\%) and Central South University of Finance and Economics (25\%) and other university (25\%, in studying). In terms of professional titles, the professor, associate professor and assistant professor account for $25 \%, 50 \%$ and $25 \%$ respectively. Secondly, they are more experienced in oversea study and familiar with the advanced teaching methods of similar courses in foreign universities. $75 \%$ of the teachers in the team have the experience of studying abroad. They have systematically studied similar courses in the United States, Japan, Australia and other countries. Thirdly, they have rich experience in theoretical teaching and practical work. All teachers in the team have been engaged in teaching related to Audit and Assurance Service for several years and have at least one year's practice training experience in the National Audit Office. $50 \%$ of them have rich experience in international auditing and they participated in the United Nations audit in 2013.

\subsection{Selection of High Quality Teaching Materials}

\subsubsection{Selection of Advanced Textbooks}

In professional English teaching, the selection of textbooks is very important. Audit and Assurance Service uses the one of the most classic and authoritative original textbook in the world as the main teaching material, which is Auditing and Assurance Service: an integrated approach (15th Edition), edited by Alvin A. Arens, Randal J. Elder, and Mark S. Beasley. This textbook is highly praised by auditing theorists, educators and practitioners and is recognized as the best book for systematically learning and comprehensively grasping the modern western auditing theory and practice, especially in the United States. The most important reason is that it is for the first time that proposed and advocated the idea of transaction cycle audit and focused on the audit decision-making process in the audit of financial statements and its integration audit with internal control over financial reporting, aiming at presenting the latest globally recognized content of the auditing with practical examples. The selection of this textbook not only realizes the synchronization with the developed countries, but also guarantees the universal knowledge system being spread. Through this course, students can not only experience the most authentic English language environment, but also get a better understanding of the practices and rules of American auditing and international auditing. Besides the textbook, according to the principle of selecting textbooks in the university, another 3 textbooks are selected as references, including Auditing Cases: An Interactive Approach (5th Ed) compiled by Mark S. Beasley, Frank A. Buckless, Steven M. Glover, Douglas F. Prawitt, Auditing compiled by the Chinese Association of Certified Public Accountants, and Standards of the Chinese Association of Certified Public Accountants. The selection is based on the difficulty of textbooks, professional level, domestic and foreign environment, theory and practice, and all key contents of these textbooks are included in the examination scope.

\subsubsection{Construction of Teaching Auxiliary Materials}

In the course teaching process, the teaching group prepares some teaching documents such as syllabus, text teaching plan, electronic teaching plan, cases and problems, etc. At the same time, in order to facilitate students' extra-curricular learning and communication, the following work has also been done. (1) Recommending some 
famous financial and economic websites to students, such as the American Stock Exchange, American Institute of Certified Public Accountants, China Securities Regulatory Commission, Shanghai Stock Exchange and Shenzhen Stock Exchange, as well as the online guides of world-famous exchanges such as New York, Hong Kong and London. Through browsing and reading relevant information of listed companies and financial news, the students can have an understanding of the latest industry trends and future career choices and development. (2) Providing students with some well-known audit cases at home and abroad. Students are required to read various supplementary materials on auditing theory and practice, and to analyze and interpret the relevant contents based on the knowledge they have learned. (3) Introducing the electronic database of Chinese and foreign languages that can be used in the university, by which students can browse and download papers of audit from international journals so that they can understand the hot issues of the audit theory and practice. As a result, their professional vision can be expanded which help them preparing for writing professional papers in the future.

\subsection{Innovative Curriculum System and Teaching Content Planning}

Audit and Assurance Service is a highly theoretical and practical course. Based on the principle of taking Chinese students as the main body while giving consideration to foreign students, the course content are designed into theoretical part and practical part.

\subsubsection{Perfect Theoretical System}

The original English textbook has a sound theoretical system and a lot of content. Due to the limitation of class hours, the course group deleted the contents which were not or rarely involved in the audit teaching materials of China. The theoretical part focuses on the audits of financial statements and internal control over financial reporting of certified public accountants. Thus, the system mainly includes the profession of auditing, the process of auditing, application of the audit process to the sales and collection cycle, application of the audit process to other cycles and completing the audit.

\subsubsection{Appropriate Practical Teaching}

Course experiment is an important part of course teaching through which students can deepen their understanding of knowledge that teacher taught in class and master the application methods of theoretical knowledge. Audit and Assurance Service is a course with strong theoretical and practical nature, which is based on the cultivation of the students' practical ability of audit. Since no corresponding English training software has been found in China till now, the teaching group decides to add practical part to the teaching contents, aiming at cultivating students' practical ability of using theoretical knowledge. This makes the curriculum system more perfect. Its design idea is to train senior professionals with innovative spirit and practical ability. According to the characteristics of this course, the teaching group designs a semester project, which can embody the application of audit theory and the high participation of students.

The semester project is assigned in the second week of the beginning of the semester. The students are required to complete the corresponding part according to the learning progress of the course during the semester and to present the result in groups at the end of the semester. Through several years of practice, the following abilities of students have been effectively trained. (1) The project is carried out in groups, with the division as well as cooperation among members, reflecting the characteristics of the audit work and improving students' communication and teamwork skills. (2) The core task of the project is to visit the SEC website and download the Form 10-K Filing data of companies listed on New York and NASDAQ exchanges. The students simulate the audit procedure manually in the form of answering questions and place the audit in a real environment. This can enhance the students' ability of analyzing and solving problems by the application of theoretical knowledge. (3) The whole project is required to be completed in English from data collection and sorting, question answering, report submission, PPT making to project presentation. It improves students' written and oral professional English skills as well as their ability to use electronic equipment and related software.

\subsection{Application of Modern Teaching Tools and Methods}

This course attaches importance to not only the teaching of knowledge and skills, but also the cultivation of students' abilities. In order to improve the teaching efficiency and effectiveness, the teaching group of the course pays special attention to the innovation and reform of teaching methods and techniques in the daily teaching process.

\subsubsection{Diversification of Teaching Methods}

Different methods are used in the teaching process to help students understand how to analyze the audit cases in practice, how to write professional papers, and how to combine theory and practice of auditing. These methods 
are described as follows.

(1) Heuristic teaching. In the process of teaching, the teaching group has designed hierarchical, progressive and even leading problems for the main concepts, core theories and the main methods of analyzing problems, which can help students to think actively, master basic knowledge quickly, and improve the ability to analyze and solve problems independently. For example, when teaching the auditor's professional ethics, students are inspired to think about the importance and necessity of auditing professional ethics by introducing the moral and immoral behaviors in daily life, which can deepen students' understanding of observing professional ethics.

(2) Case-based teaching. At the beginning of the key chapters teaching, teachers will introduce real cases to attract students' interest. During the explanation of theory, some targeted and classical small cases are introduced to deepen students' perceptual understanding of the theory and reduce the difficulty of understanding the theory. For example, when teaching the internal control audit, some typical cases such as Enron, WorldCom are told to help students to understand the importance of internal control and the key points of understanding and testing internal control. At the end of the chapter, the case talked about at the beginning may be discussed or explained again which can improve the students' ability of applying theoretical knowledge to solve practical problems.

(3) Research-based teaching. The teaching group encourages students to participate in scientific research activities and enhance students' scientific research ability. Teachers guide students to focus on and study hot issues related to auditing, and search and sort out relevant domestic and foreign literature so as to enhance students' awareness of scientific research. Students are also encouraged to participate in application of College Students' Innovation and Entrepreneurship Projects so as to strengthen the cultivation of students' research and innovation abilities. For the students who have a certain degree of scientific research ability, teachers will provide special guidance for their writing papers or research reports to improve their expression on research topic.

(4) Flipped classroom. The effect of traditional teacher-centered classroom teaching are often not very satisfactory because it is difficult for students to highly concentrate on the subject that the teacher taught under the passive acceptance environment. In order to stimulate students' learning enthusiasm and improve learning efficiency and effectiveness, the teaching group tries to use the mode of flipped classroom in teaching. In the practice, case analysis should be completed by grouping and their discussion result will be displayed in class, re-discussed with other groups and commented by the teacher.

\subsubsection{Modernization of Teaching Methods}

The rapid development of information technology marked by computers and softwares has played an important role in breaking through the traditional teaching method of "chalk plus blackboard". In the course of teaching Auditing and Assurance Service, we have adopted a variety of modern teaching methods to further optimize the teaching effect.

(1) Electronization of PPT and teaching plan.

The teaching group has produced all-English electronic PPT and teaching plan, made full and proper use of modern educational techniques, which liberates teachers from simple and repetitive teaching environment, enables them to save enough time to discuss with students freely and flexibly, and changes the passive situation of teachers' writing and students' recording in the past. Moreover, teaching information has been increased and the efficiency and effectiveness of teaching have also been improved.

(2) Networking of course content and teaching materials. The teaching group uploads teaching syllabus, course PPT, teaching schedule and other teaching materials to the Blackboard platform, providing reference for students at the beginning of the semester. A course website for Audit and Assurance Service is being made, which tries to design an online self-learning and evaluation system for students. Thus, students can freely choose the contents when they want to study, watch the teaching plans and PPT, or conduct case study, and then complete exercises to test the learning effect. In this way, students' autonomous learning ability can be improved.

(3) Automation of assignment release and correction. In the course of teaching, teachers arrange carefully designed exercises after each chapter to promote students to consolidate learning content and strengthen learning results. The teaching group tries to use AIB platform for homework management to accelerate the process of networking, informatization and automation of students' homework. Compared to the previous homework assignments and correction methods, the network test system platform can not only greatly reduce the workload of teachers in correcting homework, but also get a comprehensively understanding of each student on a timely basis. 


\subsubsection{Scientific Design of Course Evaluation}

Audit and Assurance Service is assessed and evaluated in English. It pays more attention to process control and assessment, and adjusts the proportion of elements that constitute students' final scores, including "attendance" (10\%), "homework" (20\%), "group project presentation" (20\%) and "final examination" (50\%). It focuses on process control and changes the assessment method that the evaluation only attaches importance to the final written test in the past, which can evaluate students comprehensively and improve the students' ability to analyze, solve problems and express themselves in English. Moreover, it is also conducive to teachers' timely response or adjustment. The evaluation system of this course is designed with reference to similar foreign courses, reflecting the diversity and accumulation of assessment elements.

Firstly, evaluation of students' attendance and homework. The teacher assesses students' attendance on an irregular basis, accounting for $10 \%$ of the final comprehensive score. Audit and Assurance Service tries to release and grade assignments on the AIBO platform. After each topic or chapter is finished, the network homework needs to be completed within the limited time. The system automatically records students' performance for each assignment, and finally forms the score of the homework, accounting for $20 \%$ of the final score. In this way, students are encouraged to pay more attention to their daily accumulation, so that they can control the path to achieve the course goal more effectively.

Secondly, the evaluation of semester project presentation. The semester project should be completed through group discussions, written reports and oral presentation in groups which accounts for $20 \%$. To prevent the participants from free-riding, besides the teacher's evaluation on the group's collective performance, the contribution of each member decided by other members of the group should also be considered when evaluating his/her score. In this way, the participation awareness and enthusiasm of the students has been increased as well as understanding the knowledge.

Finally, the evaluation of the phased examination. The final examination accounts for $50 \%$ of the total, which changes the previous pattern that the evaluation is nearly decided by the final examination. It can effectively stimulate the students' devotion to the study in usual times. In the future, the number of phased exams will be further increased and the proportion of final exams will be reduced according to the actual situation so that students can devote more time and energy to the course learning in usual times. Thus, the teaching quality of this course can also be steadily improved.

\section{Areas Needs to Be Improved}

However, there are still many defects that need to be further improved. First of all, the level of full-English teaching needs to be further improved. Due to various constraints, the teaching group of the course is currently composed of local teachers and returned overseas. Due to different cultural backgrounds and institutional systems, teachers may lack certain depth in understanding the teaching materials and thus may affect the teaching level. In the future, we will try to invite overseas experts and foreign visiting professors to give special lectures in class, or carry out in-depth exchanges and cooperation with international cooperation project universities. For example, we can continue to discuss the key points, difficulties and solutions of teaching through exchanges of lectures with cooperative universities. Because of lacking full-English language environment, there is still a gap between teachers and foreign countries in the control and application of teaching language. According to the feedback of foreign students, teachers pay much attention to the grammar and knowledge and their expression tends to be written English which lack some sense of humor. The main reason is that English is not their native language and the organizational ability of the language is relatively weak. The teaching group will increase the frequency of group discussion and lesson preparation to make the lectures more interesting and understandable. In addition, the teaching contents, teaching tools and evaluation methods need to be further improved. Compared to foreign students, Chinese students are somewhat passive in class discussions and group presentations, which may be related to students' learning habits under the traditional "cramming" teaching environment. The uneven English proficiency of students is also an important factor restricting the teaching effect. Therefore, how to improve the teaching effect with the consideration of different levels of students is also a challenge faced by this teaching group. The teaching group will continually reform the teaching methods and evaluation methods, explore the test grading of students at the beginning of the semester, and adopt different teaching methods based on the different grading. Of course, different assessment methods should also be developed to further enhance students' interest in learning and improve learning results.

\section{Conclusions}

In the national-wide, the full-English teaching of auditing major is generally in the exploratory stage. After several years of construction, Nanjing Audit University has made some achievements in this field which can be 
summarized as follows. As far as the selection of teaching materials, the provision of basic teaching resources and the way of testing are concerned, the course of Audit and Assurance Service is at a fairly higher level than similar courses at home and abroad. In terms of the depth and breadth of teaching contents, the elaboration, discussion and extension of some specific issues will be more detailed than that of foreign countries because that domestic teaching is more focused on textbooks and the class hours are relatively abundant. However, there are still many defects that need to be further improved, including the level of teaching group, teaching contents, teaching tools and evaluation methods, all of which will be improved continually.

\section{Acknowledgements}

This paper is supported by the Top-notch Academic Programs Project of Jiangsu Higher Education Institutions: Auditing (No., PPZY2015A077), the Priority Academic Program Development of Jiangsu Higher Education Institutions, Postgraduate Education Reform Project of Jiangsu Province (JGLX18 033), and Jiangsu Provincial Excellent English Teaching Courses for Foreign Students of 2016 (No., SJWB[2016]19).

\section{References}

Deng, J. B., Yu, D. M., \& Wen, S. G. (2006). Teaching Experience of Anatomy, Histology and Embryology for Foreign Students. Researches in Medical Education, 5(11), 1051-1053. https://doi.org/10.3760/cma.j.issn.2095-1485.2006.11.030

Gang, X., Su, Y., Yang, M. H., \& Li, K, S. (2012). USMLE Used as Evaluation Approach for Medical English-immersed Teaching. China Higher Medical Education, (3), 54-55. https://doi.org/10.3969/j.issn.1002-1701.2012.03.025

Li, Y. (2017). An Empirical Study on the Effect of English Teaching in Colleges and Universities. Foreign Language in China, (1), 61-69. https://doi.org/ZGWE.0.2017-01-010

Ma, J., Gou, L. F., \& Han, X. B. (2019). Course Construction and Practice Research on Automatic Control Theory. Education Modernization, (42), 120-123. https://doi.org/10.16541/j.cnki.2095-8420.2019.42.042

Sun, J. W. (2017). A Study on English Learning Anxiety of College Students in an International class. Ningbo University. https://doi.org/CNKI:CDMD:2.1017.871409

Wang, Z. Z., Hu, J. H., \& Guo, Z. Q. (2010). English Teaching Practice and Experience for Indian Medical Students. Journal of Ningxia Medical University, 32(4), 555-556. https://doi.org/10.3969/j.issn.1674-6309.2010.04.035

Wu, H. Y., Li, Q. S., Zhang, C. J., \& Li, H. (2008). English Teaching Experience for Foreign Students in Western Medical Universities. Journal of Shanxi Medical University, 10(2), 214-216. https://doi.org/10.3969/j.issn.2095-1450.2008.02.041

Yu, Q. H., \& Yang, Q. (2018). Discussion on the Full-English Teaching Mode of College on International Students' Professional Courses under the New Situation. Survey of Educator, 7(21), 128-130. https://doi.org/10.16070/j.cnki.cn45-1388/g4s.2018.21.042

Zhou, K. X., Shi, L., Luo, C. L., \& Xiao, C. H. (2008). Evaluation of Full-English Teaching Effectiveness on Basic Nursing. Journal of Nursing Training, (21), 1931-1933. https://doi.org/10.3969/j.issn.1002-6975.2008.21.005

Zhu, W. Z. (2005). Investigation and Analysis of the English Immersion Education. International Economics and Trade Research, (6), 50-53. https://doi.org/10.3969/j.issn.1002-0594.2005.z1.013

\section{Copyrights}

Copyright for this article is retained by the author(s), with first publication rights granted to the journal.

This is an open-access article distributed under the terms and conditions of the Creative Commons Attribution license (http://creativecommons.org/licenses/by/4.0/). 